\title{
Role of physiological status of ruminant animals reared in Lafia metropolis on gastrointestinal parasites burden
}

\author{
M. M. Adua, K. O. Idahor ${ }^{\star}$ and U. M. Sambo \\ Department of Animal Science, Nasarawa State University, Keffi, Shabu-Lafia Campus, P.M.B. 135, Lafia, 950101, \\ Nigeria. \\ *Corresponding author: Email: omokingida@yahoo.com
}

Copyright (C) 2017 Adua et al. This article remains permanently open access under the terms of the Creative Commons Attribution License 4.0, which permits unrestricted use, distribution, and reproduction in any medium, provided the original work is properly cited.

Received 3rd June, 2017; Accepted 22nd June, 2017

\begin{abstract}
In Nigeria, cattle, sheep and goats are reared basically under extensive production system. In some cases, these animals irrespective of their species and breeds are reared together especially under the modified urban or peri-urban system, hence, the possibility of cross-transmission of gastrointestinal parasites resulting in heavy parasites burden. There are several reports on parasites control measures involving biological and cultural techniques even the use of unsafe chemicals. Yet, little or nothing is known about sex, age and breed as physiological status in gastrointestinal parasites control strategy. Hence the present study was aimed at investigating the susceptibility of ruminants based on sex, age and breed-type. In order to achieve this, a total of 2, 400 ruminants (1, 500 cattle, 450 sheep and 450 goats) that have not been dewormed for at least 6 months prior to the study were examined. Faecal samples were collected from 800 ruminant animals (500 cattle, 150 sheep and 150 goats) based on sex, age and breedtype each which were processed for microscopic examinations. Results showed that $43.4 \%$ (bull), $41.6 \%$ (cow), $18.7 \%$ (ram), 16.6\% (ewe), 11.3\% (buck) and 14.0\% (doe) were infected with gastrointestinal parasites. In all the species examined, each age category was infected and the young ones were observed to seemingly exhibit more susceptibility than the adults. The prevalence rate of gastrointestinal parasites varied between 22.4 and $62.6 \%$ in cattle breeds, 3.3 and $16.0 \%$ in sheep while 6.0 to $8.7 \%$ was recorded in goats. It was observed that Haemonchus, Fasciola and Strongyle species infected the cattle while, Entamoeba, Moniezia, Paramphistomum and Haemonchus species were found in both sheep and goats. In each case, mixed infections were recorded therefore sex, age and breed may perhaps not play significant roles in gastrointestinal parasites control in ruminant animals reared in Lafia metropolis.
\end{abstract}

Keywords: Cattle, goats, gastrointestinal parasites, peri-urban system, sheep.

\section{INTRODUCTION}

Ruminant animals such as cattle, sheep and goats are reared basically for milk, meat, hide and skin as well as manure. Meanwhile, cattle could be used for farm work as well as transportation of goods and services. Ruminant animal production system could be classified as intensive, semi-intensive and extensive, depending on the financial buoyancy of the farmer and the local climatic conditions. In Lafia metropolis, ruminant animals are reared under "modified extensive production system" that could be referred to as urban or peri-urban production system. In this system, the rearers live around the metropolis where demand for milk and meat products is relatively high. Although, this production system is largely traditional where the ruminant animals graze around the metropolis as well as feed on agro-industrial by-products. The milk and meat products are sold directly to the consumers at urban markets without the services of the middlemen with their attendant disadvantages. Thus, urban or peri-urban ruminant animal production strategy could be a veritable source of livelihood for stakeholders and households in the cities and cosmopolitans. More importantly, it may enhance higher animal protein intake among the urban dwellers than the rural dwellers without such opportunities. However, the animal species raised in this kind of production system, may be vulnerable to parasitic infections. This may be due to the unhygienic environment characterized by human open defaecation, lack of milk and meat products inspection by experts 
before sales at the urban markets. This scenario may result in higher risk of infections and recycling of parasitic eggs, oocysts and infective larvae among the animals and the people living in the metropolis.

According to Love and Hutchinson (2003), parasitic infections are generally regarded as the most prevalent and important health problems of grazing ruminants. More so, Ntonifor et al. (2013) stated that gastrointestinal tract parasites are known to be widespread thus, limit ruminant animal production in many parts of the world. There are several reports on the economic losses of ruminant animals that were hinged on gastrointestinal parasites infection (Ntonifor et al., 2013; Kanyan et al., 2009; Asif et al., 2008; Odoi, 2007; Ng'ang'a et al., 2004; Love and Hutchinson, 2003). Asif et al. (2008) reported that endoparasites infection resulted in huge economic losses to the tune of $19.7 \mathrm{~m}$ per year. Consequently, to avert this level of colossal economic losses, physiological status of the ruminant animals may play significant roles. Hence, this study was aimed at examining the effects of sex, age and breed as physiological status in gastrointestinal parasites control strategy in cattle, sheep and goats reared in Lafia metropolis.

\section{MATERIALS AND METHODS}

\section{Brief description of the study area and climatic condition}

The study was conducted in the months of May and June in Lafia located within the north central zone of Nigeria. Lafia is situated on latitude $08^{\circ} 35^{\prime} \mathrm{N}$, longitude $08^{\circ} 34^{\prime} \mathrm{E}$ with an altitude of $181 \mathrm{~m}$ above sea level, temperature ranging from 32 to $35^{\circ} \mathrm{C}$, relative humidity between 58 and $63 \%$, average day light of 9 to $12 \mathrm{~h}$ and average rainfall of $1,400 \mathrm{~mm}$ per annum (NIMET, 2011). The vegetation consists of different species of trees, shrubs, leguminous browse plants and grasses with fairly undulated terrain.

\section{Study design}

A total of 2,400 ruminant animals ( 1,500 cattle, 450 sheep and 450 goats) under peri-urban production system and have not been dewormed for at least 6 months were examined. Faecal samples were randomly collected from 10 animals in every 20 herds of cattle, sheep and goats reared in Tudun Gwandara, Shinge, Nasarawa State Polytechnic Students Village and Shabu in Lafia metropolis. Although it was very tedious, the faecal samples were collected directly from the anus in clean containers during defaecation in order to minimize contamination. Faecal samples were collected from a total of 800 ruminant animals (500 cattle, 150 sheep and 150 goats) each based on sex, age and breed respectively. The samples collected were properly labeled and promptly transported to the Parasitology
Laboratory Unit, Dalhatu Araf Specialist Hospital, Lafia, for identification of gastrointestinal parasites. This routine was carried out every morning before taking the animals out for grazing and the period of faecal sample collection lasted for 8 weeks (May and June). To minimize error, each sample collected was analyzed separately and those that were not analyzed on the same day were discarded and sample collection was repeated.

\section{Physiological status determination}

The age of the animals examined was given by the rearers but the animals were categorized into the various age groups by dentition technique as described by Merck (2015a) in cattle and NARI (2003) in sheep and goats. The breeds were identified by the rearers and were confirmed by the phenotypic and morphological traits observed as described by FAO (2011) in animals. The sex of the animals was identified by visual observation before faecal sample collection.

\section{Data collection and statistical analysis}

Two grams of the freshly collected faecal samples were processed for microscopic examination as illustrated in centrifuge floatation, sedimentation techniques and identification procedure of gastrointestinal parasites eggs, oocysts and infective larvae (Christensen et al., 1984; Soulsby, 1982; MAFF, 1977). The data collected were based on the age, breed and sex of the ruminant animals and these were considered as physiological status in this study. All the data collected were subjected to descriptive statistics and where applicable analysis of variance procedure according to GenStat (2008) was adopted and the mean values were however compared only within each animal species.

\section{RESULTS}

Expressed in Table 1 is the effect of sex on gastrointestinal parasites burden in ruminant animals reared in Lafia metropolis. The mean parasites burden value did not differ significantly $(P>0.05)$ among each of the animal species. In a total of 250 each of the bulls and cows examined, 217 (representing 43.4\%) and 208 (representing $41.6 \%$ ) respectively were infected with gastrointestinal parasites. This culminated in 425 (representing $85.0 \%$ ) out of the 500 cattle examined with mean parasites burden values between 2.52 and 2.58 . Haemonchus, Fasciola and Strongyle species were found in both sexes.

In each of the 75 rams and ewes examined, 28 (representting 18.7\%) and 25 (representing 16.6\%) respectively were infected with gastrointestinal parasites resulting in 53 (representing $35.3 \%$ ) out of the 150 sheep examined. The mean parasites burden value was slightly higher 
Table 1. Effect of sex on gastrointestinal parasite burden in cattle, sheep and goats reared in Lafia metropolis.

\begin{tabular}{|c|c|c|c|c|c|}
\hline $\begin{array}{l}\text { Animal } \\
\text { species }\end{array}$ & Sex & $\begin{array}{l}\text { Frequency } \\
\text { of infection }\end{array}$ & $\begin{array}{c}\text { Prevalence } \\
(\%)\end{array}$ & $\begin{array}{c}\text { Mean } \\
\text { parasites burden }\end{array}$ & Identified parasites \\
\hline \multirow{5}{*}{$\begin{array}{l}\text { Cattle } \\
(\mathrm{N}=500)\end{array}$} & Bull $(\mathrm{N}=250)$ & 217 & 43.4 & 2.52 & Haemonchus, Fasciola and Strongyle spp. \\
\hline & Cow $(\mathrm{N}=250)$ & 208 & 41.6 & 2.58 & Haemonchus, Fasciola and Strongyle spp. \\
\hline & Total & 425 & 85.0 & - & - \\
\hline & LSD & - & - & 0.15 & - \\
\hline & Probability & - & - & 0.45 & - \\
\hline \multirow{6}{*}{$\begin{array}{l}\text { Sheep } \\
(N=150)\end{array}$} & $\operatorname{Ram}(\mathrm{N}=75)$ & 28 & 18.7 & 2.28 & Entamoeba and Moniezia spp. \\
\hline & Ewe $(\mathrm{N}=75)$ & 25 & 16.6 & 2.29 & Paramphistomum and Moniezia spp. \\
\hline & Total & 53 & 35.3 & - & - \\
\hline & SEM & - & - & 0.120 & - \\
\hline & LSD & - & - & 0.107 & - \\
\hline & Probability & - & - & 0.977 & - \\
\hline \multirow{6}{*}{$\begin{array}{l}\text { Goats } \\
(N=150)\end{array}$} & Buck (N=75) & 17 & 11.3 & 2.32 & Moniezia and Entamoeba spp. \\
\hline & Doe $(N=75)$ & 21 & 14.0 & 2.20 & Entamoeba and Paramphistomum spp. \\
\hline & Total & 38 & 25.3 & - & - \\
\hline & SEM & - & - & 0.121 & - \\
\hline & LSD & - & - & 0.383 & - \\
\hline & Probability & - & - & 0.538 & - \\
\hline
\end{tabular}

SEM: Standard error of mean; LSD: Least significant difference; Spp: Species; N: Sample size.

(2.29) in the ewes that were infected with Moniezia and Paramphistomum species compared to 2.28 in ram where Entamoeba and Moniezia species were found.

Out of the 150 goats examined, 21 does (representing $14.0 \%$ ) compared to 17 (representing $11.3 \%$ ) bucks were infected with Entamoeba, Moniezia and Paramphistomum species with higher (2.32) mean parasites burden recorded in the bucks. It was observed that a total of 38 (representing $25.3 \%$ ) of the 150 goats examined were infected with at least two gastrointestinal parasites.

The effect of age on gastrointestinal parasites burden on cattle, sheep and goats reared in Lafia metropolis is presented in Table 2. There were no statistical differences $(P>0.05)$ in the mean parasites burden values in each of the animal species. Meanwhile, out of the 500 cattle examined, as high as 437 (representing 87.4\%) were infected with at least 2.4 parasite species which included Haemonchus, Strongyle and Fasciola. Absolutely (100\%) all of the 8-teeth, 98 (representing $19.6 \%$ ) of the 100 2-teeth and 95 (representing 19.0\%) of the 100 6-teeth cattle examined were infected with parasites. Although, the 3-teeth cattle examined were very few, they had the highest (3.0) mean parasites burden.

Among the 150 sheep examined, 53 (representing $35.4 \%$ ) were infected with parasites with the highest (2.4) mean parasites burden observed in milk-teeth and 8teeth respectively. The least (2.1) mean parasites burden value was recorded in 6-teeth and the identified parasites in sheep were Haemonchus, Moniezia, Entamoeba, Strongyle and Paramphistomum species.
In a total of 150 goats examined, 7 out of the 30 2-teeth were infected with Moniezia and Entamoeba species. Whereas, among 40 each of the 4-teeth, 6-teeth, and 8teeth goats examined, 7,5 and 9 respectively were infected with gastrointestinal parasites comprised of Paramphistomum, Haemonchus, Moniezia, Strongyle and Entamoeba species.

Table 3 shows the influence of breed-type on gastrointestinal parasites burden in cattle, sheep and goats reared in Lafia metropolis. There were no significant differences $(P>0.05)$ in the mean parasites burden values across the animal species and breeds. Except in cattle, where White Fulani breed value (2.6) was statistically different $(\mathrm{P}<0.05)$ from that of Sokoto Gudali (2.4). Meanwhile, in a total of 360 White Fulani breed examined, 313 (representing 62.6\%) were infected with gastrointestinal parasites. Whereas, 112 (representing 22.4\%) of the 140 Sokoto Gudali breed examined were infected. The gastrointestinal parasites found in White Fulani were Haemonchus, Fasciola and Strongyle species, while those of Sokoto Gudali were Heamonchus and Strongyle species.

In a total of 150 sheep examined, 61 (representing 40.6\%) were infected with gastrointestinal parasites which included Moniezia, Paramphistomum and Entamoeba species. The mean parasites burden value was highest (2.4) in Uda, followed by Yankasa (2.39), Balami (2.18) and West African Dwarf sheep (2.0). In each of the 40 Yankasa, Balami and Uda breeds, 15 (representing 10.0\%), 24 (representing 16.0\%) and 17 (representing $11.3 \%$ ) were infected with gastrointestinal parasites whereas, only 5 (representing $3.3 \%$ ) out of the 
Table 2. Effects of age on gastrointestinal parasites burden on cattle, sheep and goats reared in Lafia metropolis.

\begin{tabular}{|c|c|c|c|c|c|}
\hline $\begin{array}{l}\text { Animal } \\
\text { species }\end{array}$ & Age & $\begin{array}{l}\text { Frequency } \\
\text { of infection }\end{array}$ & $\begin{array}{c}\text { Prevalence } \\
(\%)\end{array}$ & $\begin{array}{c}\text { Mean } \\
\text { parasite burden }\end{array}$ & Identified parasites \\
\hline \multirow{10}{*}{$\begin{array}{l}\text { Cattle } \\
(\mathrm{N}=500)\end{array}$} & Milk-teeth $(\mathrm{N}=90)$ & 52 & 10.4 & 2.6 & Haemonchus, Strongyle and Fasciola spp. \\
\hline & 2-teeth $(\mathrm{N}=100)$ & 98 & 19.6 & 2.4 & Strongyle and Haemonchus spp. \\
\hline & 3-teeth ( $N=100)$ & 6 & 1.2 & 3.0 & Strongyle, Haemonchus and Fasciola spp. \\
\hline & 4-teeth $(\mathrm{N}=100)$ & 86 & 17.2 & 2.5 & Strongyle, Haemonchus and Fasciola spp. \\
\hline & 6-teeth $(\mathrm{N}=100)$ & 95 & 19.0 & 2.4 & Strongyle and Haemonchus spp. \\
\hline & 8-teeth $(\mathrm{N}=100)$ & 100 & 20.0 & 2.7 & Haemonchus, Strongyle and Fasciola spp. \\
\hline & Total & 437 & 87.4 & - & - \\
\hline & SEM & - & - & 0.078 & - \\
\hline & LSD & - & - & 0.217 & - \\
\hline & Probability & - & - & 0.151 & - \\
\hline \multirow{9}{*}{$\begin{array}{l}\text { Sheep } \\
(N=150)\end{array}$} & Milk-teeth $(\mathrm{N}=30)$ & 7 & 4.7 & 2.4 & Strongyle and Haemonchus spp. \\
\hline & 2 -teeth $(\mathrm{N}=30)$ & 6 & 4.0 & 2.3 & Paramphistomum and Entamoeba spp. \\
\hline & 4-teeth $(\mathrm{N}=30)$ & 13 & 8.7 & 2.2 & Moniezia and Paramphistomum spp. \\
\hline & 6 -teeth $(\mathrm{N}=30)$ & 8 & 5.3 & 2.1 & Moniezia and Haemonchus spp. \\
\hline & 8-teeth $(\mathrm{N}=30)$ & 19 & 12.7 & 2.4 & Strongyle and Moniezia spp. \\
\hline & Total & 53 & 35.4 & - & - \\
\hline & SEM & - & - & 0.133 & - \\
\hline & LSD & - & - & 0.377 & - \\
\hline & Probability & - & - & 0.709 & - \\
\hline \multirow{8}{*}{$\begin{array}{l}\text { Goats } \\
(\mathrm{N}=150)\end{array}$} & 2-teeth $(\mathrm{N}=30)$ & 7 & 4.7 & 2.3 & Moniezia and Entamoeba spp. \\
\hline & 4-teeth $(\mathrm{N}=40)$ & 7 & 4.7 & 2.0 & Paramphistomum and Strongyle spp. \\
\hline & 6 -teeth $(\mathrm{N}=40)$ & 5 & 3.3 & 2.4 & Haemonchus and Moniezia spp. \\
\hline & 8-teeth $(\mathrm{N}=40)$ & 9 & 6.0 & 2.3 & Moniezia and Entamoeba spp. \\
\hline & Total & 28 & 18.7 & - & - \\
\hline & SEM & - & - & 0.146 & - \\
\hline & LSD & - & - & 0.427 & - \\
\hline & Probability & - & - & 0.379 & - \\
\hline
\end{tabular}

SEM: Standard error of mean; LSD: Least significant difference; Spp: Species; N: Sample size.

30 West African Dwarf sheep were infected.

In each of the breeds of goats examined, West African Dwarf goats had the least (9 representing 6.0\%) infection rate while the highest (13 representing $8.7 \%$ ) was recorded in Sahel breed which was closely followed by 12 (representing 8.0\%) observed in Red Sokoto. Contrarily, West African Dwarf goats had the highest (2.43) mean parasites burden value followed by Red Sokoto (2.20) and Sahel (2.18). However, out of a total of 150 goats examined, 34 (representing 22.7\%) were infected with Entamoeba, Moniezia and Paramphistomum species.

\section{DISCUSSION}

\section{Role of sex in gastrointestinal parasites burden in ruminants}

The results showed that as high as $85.0 \%$ of the cattle examined were infected with gastrointestinal parasites.
This value was higher than $56.7 \%$ reported by Ntonifor et al. (2013) but was similar to the value recorded in Biu et al. (2009) and Fikru et al. (2006). The observed disparity could be largely due to the animal sample size and perhaps the laboratory protocols used in the studies. Although, the prevalence rate of the gastrointestinal parasites was slightly higher in the bulls, the mean parasites burden value was apparently higher in the cows. Meanwhile, both sexes were infected with Haemonchus, Fasciola and Strongyle, therefore, the observation could be a mere coincidence and probably not due to sex of the cattle. It was shown that $35.3 \%$ of the sheep examined was infected with gastrointestinal parasites and the value was less than $80.0 \%$ recorded by Maichomo et al. (2004) and $70.0 \%$ reported by Ntonifor et al. (2013). The differences may be adduced to the population size of the animals and probably due to the laboratory protocols adopted in the studies. It was observed that the rams were more infected than the ewes. While the ewes were infected with Paramphistomum and Moniezia species, the rams were 
Table 3. Influence of breed-type on gastrointestinal parasites burden in cattle, sheep and goats reared in Lafia metropolis.

\begin{tabular}{|c|c|c|c|c|c|}
\hline $\begin{array}{l}\text { Animal } \\
\text { species }\end{array}$ & Breed-type & $\begin{array}{l}\text { Frequency } \\
\text { of infection }\end{array}$ & $\begin{array}{c}\text { Prevalence } \\
(\%)\end{array}$ & $\begin{array}{c}\text { Mean } \\
\text { parasites burden }\end{array}$ & Identified parasites \\
\hline \multirow{6}{*}{$\begin{array}{l}\text { Cattle } \\
(\mathrm{N}=500)\end{array}$} & White Fulani $(\mathrm{N}=360)$ & 313 & 62.6 & $2.6^{\mathrm{a}}$ & Haemonchus, Strongyles and Fasciola spp. \\
\hline & Sokoto Gudali (N=140) & 112 & 22.4 & $2.4^{b}$ & Strongyles and Haemonchus \\
\hline & Total & 425 & 85.0 & - & - \\
\hline & SEM & - & - & 0.044 & - \\
\hline & LSD & - & - & 0.173 & - \\
\hline & Probability & - & - & 0.001 & - \\
\hline \multirow{8}{*}{$\begin{array}{l}\text { Sheep } \\
(N=150)\end{array}$} & Yankasa $(\mathrm{N}=40)$ & 5 & 10.0 & 2.39 & Moniezia and Entamoeba spp. \\
\hline & Balami $(\mathrm{N}=40)$ & 24 & 16.0 & 2.18 & Paramphistomum and Entamoeba spp. \\
\hline & WAD Sheep $(\mathrm{N}=30)$ & 5 & 3.3 & 2.00 & Paramphistomum and Moniezia spp. \\
\hline & Uda $(\mathrm{N}=40)$ & 17 & 11.3 & 2.40 & Paramphistomum and Entamoeba spp. \\
\hline & Total & 61 & 40.6 & - & - \\
\hline & SEM & - & - & 0.12 & - \\
\hline & LSD & - & - & 0.34 & - \\
\hline & Probability & - & - & 0.472 & - \\
\hline \multirow{7}{*}{$\begin{array}{l}\text { Goats } \\
(N=150)\end{array}$} & Sahel $(N=50)$ & 13 & 8.7 & 2.18 & Moniezia and Paramphistomum spp \\
\hline & Red Sokoto $(\mathrm{N}=50)$ & 12 & 8.0 & 2.20 & Moniezia and Entamoeba spp. \\
\hline & WAD goats $(\mathrm{N}=50)$ & 9 & 6.0 & 2.43 & Entamoeba and Moniezia spp. \\
\hline & Total & 34 & 22.7 & - & - \\
\hline & SEM & - & - & 0.141 & - \\
\hline & LSD & - & - & 0.413 & - \\
\hline & Probability & - & - & 0.515 & - \\
\hline
\end{tabular}

a,b: Mean values on the same column with different superscript differ significantly at $5 \%$ probability; SEM: Standard error of mean; LSD: Least significant difference; spp: Species; N: Sample size; WAD: West African Dwarf.

infected with Entamoeba and Moniezia species. What could be responsible for this observation is not clear, but it could be due to parasites epidemiology of the study areas and possibly not as influenced by sex of the sheep. The study revealed that $25.3 \%$ of the goats examined were infected with gastrointestinal parasites. This value was far less than over $90.0 \%$ (Ntonifor et al., 2013) and $82.0 \%$ (Maichomo et al., 2004) respectively reported in goats. Although, the parasites prevalence rate was seemingly higher in the does, both sexes were infected with at least two species of gastrointestinal parasites. In the does, Entamoeba and Paramphistomum species were found whereas, Moniezia and Entamoeba species were identified in bucks. The cause of these differences may not be clear but could be due to the epidemic nature of parasites in the study areas and probably not due to sex.

\section{Role of age in gastrointestinal parasites burden in ruminants}

Results indicated that all the age categories of the cattle examined were infected with gastrointestinal parasites and the prevalence rate was observed to be higher than a range of 27.4 to $69.2 \%$ reported elsewhere in cattle
(Maichomo et al., 2004). This observation could be partly due to the management practices and perhaps animal sample size differences in the studies. The seemingly observed high prevalence of gastrointestinal parasites in the calves and heifers rather suggested parasites epidemic, poor management system in the study areas and probably not as a result of age of the animals studied. More significantly, mixed infections observed in all the age categories may lead to decreased production efficiency earlier reported in ruminant animals (Asif et al., 2008; Kagira and Kanyari, 2001). It was observed that all the age groups of the sheep were infected with gastrointestinal parasites. The seemingly high parasites burden recorded in the milk-teeth and 2-teeth seem inexplicable, because at these stages they are expected to only nibble at the pasture just to mimic the grazing habit of the dam. However, it could be solely due to high prevalence of parasites in the areas, which may have resulted in early transmission from the dam during grooming and not probably as influenced by age. Meanwhile, the recorded prevalence rate was less than $80 \%$ reported in Maichomo et al. (2004) but similar to the range of 2.9 to $28.8 \%$ observed by Ntonifor et al. (2013). The disparities could be largely due to the management practices adopted in the studies, animal sample size and partly due to the time of the year when the studies were 
conducted. Unlike in cattle and sheep examined in this study, there were no milk-teeth among the goats and 3teeth was found only in cattle. The cause of these observations is not known but could be a growth phase of the animals during the study period and probably due to seasonal cyclic nature of the animal species. All the age classes of the animals studied were observed to be infected with gastrointestinal parasites, with relatively higher prevalent rate in the 2-teeth and 4-teeth respectively. This observation may be a mere coincidence and not probably due to the age thus, buttressed the reports of Asif et al. (2008) as well as Fakae (1990) that young animals were more susceptible to parasites infection. In any case, the parasites burden recorded in all the animal species studied, was similar to several observations earlier made (Ntonifor et al., 2013; Biu et al., 2009; Asif et al., 2008; Love and Hutchinson, 2003; Githigia et al., 2001).

\section{Role of breed-type in gastrointestinal parasites burden in ruminants}

It was observed that gastrointestinal parasites were more prevalent in White Fulani than in Sokoto Gudali in the study areas. This was probably a mere coincidence or possibly due to the animal sample size and perhaps not due to breed-type, because both breeds were infected with at least two different kinds of parasite species. Meanwhile, the prevalence rate in White Fulani was similar to $69.2 \%$ reported in Maichomo et al. (2004) and $56.7 \%$ recorded by Ntonifor et al. (2013) in cattle. The observed Haemonchus and Strogyle species in both White Fulani and Sokoto Gudali, lent more credence to the observations earlier made (Asif et al., 2008; Odoi et al., 2007; Agyei, 1997) that they are the most common and economically important gastrointestinal parasites in the tropics. The Fasciola species that was found only in White Fulani may be coincidental and may not be probably associated with cattle breed-type.

It was shown that Balami was seemingly more infected by gastrointestinal parasites than Uda and Yankasa whereas West African Dwarf sheep seemingly portrayed some levels of resistance in the study. Furthermore, each of the breeds was found to be infected with two parasites and Entamoeba species was common to all except West African Dwarf sheep. However, the observed Moniezia, Paramphistomum and Entamoeba contradicted the reports of Ntonifor et al. (2013) and Maichomo et al. (2004), who reported other kinds of gastrointestinal species in sheep. This could be largely due to geographical locations of the studies or possibly due to mode of parasitism and may not be probably due to the breed-type of the animals studied. The prevalence rate was lower than $73.1 \%$ recorded in Ntonifor et al. (2013) and $80.0 \%$ reported by Maichomo et al. (2004).

It was observed that Sahel and Red Sokoto goats were more infected with gastrointestinal parasites than West
African Dwarf goats. This probably suggested that West African Dwarf goats were more tolerant or resistant to gastrointestinal parasites in the study areas. Meanwhile, the highest mean parasite burden was recorded in West African Dwarf goats. It was revealed that each breed was infected with at least two different kinds of parasites. These included Moniezia and Entamoeba species that were common to all the goats except Sahel that was infected with additional Paramphistomum species. This observation was at variance with the reports of Merck (2015b), Ntonifor et al. (2013) and Maichomo et al. (2004) who reported Trichostrongylids, Strongyloides, Haemonchus and Ostertagia species in goats. The observed differences may be due to climatic conditions of the study locations, mode of parasitism and not possibly due to the goat breed-type. Meanwhile, the overall prevalence rate was much lower than 43.0 to $90.4 \%$ earlier reported in goats (Ntonifor et al., 2013; Maichomo et al., 2004). This disparity could be purely due to the animal sample size or probably the laboratory protocols adopted in the studies and perhaps not as influenced by breed-type.

\section{Conclusion}

It was observed that Haemonchus, Fasciola and Strongyle species infected cattle while Entamoeba, Moniezia, Paramphistomum and Haemonchus species were found in both sheep and goats examined. In any case, mixed infections were observed, indicative of health risk of both humans and animals in the study areas. Therefore, regular administration of dewormer to both humans and animals in the areas may become necessary. Also, fumigation of the areas may assist in minimizing the health threat posed to the metropolitans. In all, it was apparent that sex, age and breed of cattle, sheep and goats did not influence the results obtained. Thus, physiological status of ruminant animals reared in Lafia metropolis may not play significant role in gastrointestinal parasites control. However, West African Dwarf sheep and goats as well as Sokoto Gudali apparently exhibited breed superiority in gastrointestinal parasites resistance. Therefore, in depth researches in breeding and production management strategies, considering these breeds' potentials in boosting quality meat supply and reducing parasitic zoonosis is required.

\section{CONFLICT OF INTEREST}

The authors declare that they have no conflict of interest.

\section{REFERENCES}

Agyei, A. D. (1997). Seasonal changes in the level of infective Strongyle nematode larvae on pasture in the coastal savannah regions of Ghana. Veterinary Parasitology, 70, 175-183. 
Asif, M., Azeem, S., Asif, S., Nazir, S. (2008). Prevalence of gastrointestinal parasites of sheep and goats in and around Rawalpindiand Islamabad, Pakistan. J. Vet. Anim. Sci., 1, 1417.

Biu, A. A., Maimunatu, A., Salamatu, A. F., \& Agbadu, E. T. (2009). A faecal survey of gastrointestinal parasites of ruminants on the University of Maidiguri Research Farm. Intl. J. Biomed. Health Sci., 5(4), 4-15.

Christensen, P., Maisey, K., \& Perry, D. H. (1984). Radiotracking the Numbat, Myrmecobius fasciatus, in the Perup Forest of Western Australia. Austral. Wildlife Res., 11, 275288.

Fakae, B. B. (1990). The epidemiology of helminthosis in small ruminants under the traditional husbandry system in eastern Nigeria. Vet. Res. Commun., 14(5), 381-91.

FAO (2011). Draft guidelines on phenotypic characterization of animal genetic resources. Commission on genetic resources for food and agriculture. Thirteenth regular session, Rome, 18 to 22 July, 2011. http://www.fao.org/docrep/meeting/022/ am651e.pdf.

Fikru, R., Teshale, S., Reta, D., \& Yosef, K. (2006). Epidemiology of gastrointestinal parasites of ruminants in western Oromia, Ethiopia. Intl. J. Appl. Res. Vet. Med., 4(1), 51-57.

GenStat. 2008. GenStat Release 7.42 DE (PC/Windows XP) Copyright 2008, VSN International Ltd. Lawes Agricultural Trust Rothamsted Experimental Station.

Githigia, S. M., Thamsbug, S. M., Munyua, W. K., \& Maingi, N. (2001). Impact of gastrointestinal helminthes on production of goats in Kenya. Small Ruminants Res., 42(5), 21-29.

Kagira, J. M., \& Kanyari, P. W. N. (2001). The role of parasitic diseases as causes of mortality in small ruminants in a highpotential farming area in central Kenya. J. South Afri. Vet. Assoc., 72, 147-149.

Kanyan, P., Kagira, J., \& Mhoma, R. J. (2009). Prevalence and intensity of endoparasites in small ruminants kept by farmers in Kisumu Municipality, Kenya. Vet. Parasitol., 51(4), 137141.

Love, S. C. J., \& Hutchinson, G. W. (2003). Pathology and diagnosis on internal parasites in ruminants. Gross Pathology of Ruminants. Proc. 350, Post Graduate Foundation in Veterinary Science, University of Sydney, Sydney; Chapter 16, 309-338.
MAFF (1977). Ministry of Agriculture, Fisheries and Food. Manual of Veterinary Parasitological Laboratory Techniques (3rd ed), MAFF Reference Book 418. HMSo, London, pp. 129.

Maichomo, M. W., Kagira, J. M., \& Walker, T. (2004). The point prevalence of gastrointestinal parasites in calves, sheep and goats in Magadi Division, southwestern Kenya. Onderstepoort J. Vet. Res., 71, 257-261.

Merck (2015a). The Merck Veterinary Manual. Estimation of age by examination of the teeth, dental development Merck manuals 2009-2015, Merck Sharp \& Dohme Corp., a subsidiary of Merck \& Co., Inc., Kenilworth, N.J., U.S.A.

Merck (2015b). Gastrointestinal parasite of sheep and goats. 2009-2015 Merck Sharp \& Dohme Corp. a subsidiary of Merck \& Co, Inc. Kendworth N.J., USA, Pp. 1-4.

NARI (2003). How to tell the age of sheep and Goats? National Agricultural Research Institute Toktok Series Lab 013 E. Livestock Research Programme - Labu. LAE 411 Morobe Province.

Ng'ang'a, C. J., Miangi, N., Kanyari P. W. N., \& Munyua, W. K. (2004). Development, survival and availability of gastrointestinal nematodes of sheep on pastures in a semiarid area of Kajiado District of Kenya. Vet. Res. Commun., 28 (2), 491-501.

NIMET (2011). Nigeria Metrological Agencies, Synoptic Office, Lafia, Nasarawa State, Nigeria. Ntonifor, H. N., Shei, S. J., Ndaleh, N. W., \& Mbunkur, G. N. (2013). Epidemiological studies of gastrointestinal parasitic infections in ruminants in Jakiri, Bui Division, northwest region of Cameroun. J. Vet. Med. Anim. Health, 5(12), 344-352.

Odoi, A., Gathuma, J. M., Gachuri, C. K., \& Omore, A. (2007). Risk factors of gastrointestinal nematode parasite infections in small ruminants kept in small holder mixed farm in Kenya. BMC Vet. Res., 3(1), 6.

Soulsby, E. J. L. (1982). Helminthes, arthropods and protozoa of domesticated animals ( $7^{\text {th }}$ ed), Lea \& Febiger, p. 809. 